\title{
Ankle taping improves proprioception before and after exercise in young men
}

\author{
Steven Robbins, Edward Waked* and Ron Rappel† \\ Department of Mechanical Engineering, Concordia University and McGill University Centre for Studies in Aging, \\ Montreal, Canada; ${ }^{*}$ Divisions of Geriatric Medicine and Experimental Medicine, Montreal General Hospital, \\ Montreal, Canada; +Athletics Department, Concordia University, Montreal, Canada
}

\begin{abstract}
Ankle sprains are common sports injuries. Inadequate foot position awareness is thought to be the fundamental cause of these injuries. Ankle taping may decrease risk of injury through improving foot position awareness. The benefit of taping is thought to decrease with duration of exercise because of poor tape adherence to human skin. This study was a randomized, crossover, controlled comparison experiment that tested the hypothesis that ankle taping improves foot position awareness before and after exercise. A sample of 24 healthy young blindfolded volunteers, wearing their own athletic shoes, indicated perceived slope direction and estimated slope amplitude when bearing full body weight and standing on a series of blocks. The top slope of the blocks varied between $0^{\circ}$ and $25^{\circ}$, in $2.5^{\circ}$ increments, to orient the plantar surface with respect to the leg toward pronation, supination, plantarflexion, and dorsiflexion, relative to its position on a flat surface. Foot position awareness, which was considered the reciprocal of surface slope estimate error, varied with testing condition, particularly when surface slope was greater than $10^{\circ}$, presumably the most important range considering ankle injuries. In this higher range absolute position error was $4.23^{\circ}$ taped, and $5.53^{\circ}$ untaped $(P<0.001)$. Following exercise, in the higher range absolute position error was $2.5 \%$ worse when taped and $35.5 \%$ worse when untaped $(P<0.001)$. These data support the hypothesis that ankle taping improves proprioception before and after exercise. They also indicate that foot position awareness declines with exercise. Compared to barefoot data (position error $1.97^{\circ}$ ), foot position error was $107.5 \%$ poorer with athletic footwear when untaped (absolute position error $4.11^{\circ}$ ), and $58.1 \%$ worse when taped (position error $3.13^{\circ}$ ). This suggests that ankle taping partly corrects impaired proprioception caused by modern athletic footwear and exercise. Footwear could be optimized to reduce the incidence of these injuries.
\end{abstract}

(Br J Sports Med 1995; 29: 242-247)

Keywords: Ankle sprain, ankle taping, proprioception, exercise, sports medicine, biomechanics, athletic footwear, injury prevention.

Ankle sprains are the most frequently reported injury in sport. Studies have shown that $90-95 \%$ are inversions causing partial or complete rupture of the anterior talofibular ligament and occasionally the calcaneofibular ligament. ${ }^{12}$ Complete recovery from the initial injury is

Address for correspondence: Dr Steven Robbins MD, 800 RenéLévesque Blvd. West, Suite 2010, Montreal, Canada H3B 1X9. most probable, although reinjury often results in moderation or discontinuation of sports activities. ${ }^{2}$ Ankle sprains have become such a pervasive problem in certain competitive sports, such as basketball, that most participants are disabled by them every season, much to the frustration of those attempting prevention.

Ankle taping has become the principal means of preventing ankle sprains in sport. ${ }^{3}$ Whereas taping was once thought to stabilize the ankle mechanically, this now seems unlikely considering reports that show no measurable stabilizing effect of tape after as little as 20 minutes of exercise. ${ }^{4}$ Accordingly, ankle taping is now thought to prevent ankle injury mainly through improving the user's judgment of position and orientation of the plantar surface with respect to the leg. This foot position awareness, in the domain of proprioception, is usually referred to as kinaesthetic sense. ${ }^{5}$ Stated in physiological terms, this theory supposes that uniting the skin of the foot with the leg by ankle taping provides cutaneous sensory cues of plantar surface position and orientation through traction of tape either on hairy skin of the leg and foot, or plantar skin, or both. Presumably humans use this information in anticipation of foot contact with a surface either to position the plantar surface before the support phase to attenuate forces causing inversion, or to command muscle support to sustain these forces, thereby preventing ligament loading, or both. By this reasoning, ankle sprains are caused by impaired foot position awareness resulting in inadequate use of these anticipatory manoeuvres under conditions such as sports, when there is insufficient time to respond to the actual loading event.

The effect of ankle taping on foot position awareness has never been examined. We describe here a randomized, crossover, controlled comparison experiment which tests the hypothesis that ankle taping improves foot position awareness before and after exercise. It is accomplished through measuring the precision with which 12 taped and 12 untaped healthy young shod volunteers judged support surface orientation and estimated slope when bearing full body weight on a series of surfaces differing in angle and orientation before and after exercise, which consisted of playing basketball and running for 30 minutes. 


\section{Methods}

\section{Subjects}

Twenty four university students participated in this experiment on a voluntary basis. All were in good health, without disabilities affecting their ability to walk or run, or history of serious leg injuries. Mean age was 26.6 years (range 21.0-31.0, SD 2.9). Mean height was $169.9 \mathrm{~cm}$ (range 146.0-190.5, SD 9.7). Mean body weight was $71.7 \mathrm{~kg}$ (range 59.5-88.1, SD 7.7).

\section{Footwear}

Subjects wore their own athletic shoes both for testing during exercise and no-exercise sessions.

\section{Support surfaces}

Support surfaces consisted of blocks constructed of textured melamine covered particle board, with centre point height of $20 \mathrm{~cm}$ and surface dimensions of $30 \mathrm{~cm} \times 30 \mathrm{~cm}$. The top surface of each block was sloped at a different angle ranging from $0^{\circ}$ to $25^{\circ}$ from the horizontal in increments of $2.5^{\circ}$. Through rotation of blocks, surface slopes of between $0^{\circ}$ and $25^{\circ}$ were attained so as to place the plantar surface of subjects in supination, pronation, plantarflexion, and dorsiflexion, relative to the position on a flat surface.

\section{Ankle taping procedure}

Ankle taping was performed by a certified athletic therapist from the sports medicine clinic at Concordia University. Before taping, skin was shaved, cleansed, and dried. The taping procedure was the Gibney basket weave with a double heel lock, using $37 \mathrm{~mm}$ Johnson \& Johnson coach's adhesive tape applied directly to the skin. This method was chosen because it was most widely used among competitive athletes surveyed.

\section{Conditions}

Each subject participated in two testing sessions: exercise and a no-exercise control. In the exercise condition, subjects performed basketball and running for a 30 minute period. Conversely, subjects in the noexercise condition rested in a non-weightbearing position for 30 minutes. In each testing session, subjects were assigned either to a taped or an untaped group in a counterbalanced pattern. Subjects in the taping group had both ankles taped. Ankle tape was not applied to subjects in the untaped group, but conditions were otherwise identical to the taping group (Table 1).

\section{Testing method}

Magnitude estimation is the form of psychophysical direct scaling used in the present experiment. By this method, the subject estimates, usually with a ratio scale, perceived amplitude of sensory continua. ${ }^{\circ}$ This validated method was popularized by Stevens and has been used to examine a host of sensory stimuli in humans. ${ }^{78}$ Although quantification of subjective phenomena may convey a certain imprecision, these methods are extremely sensitive and reliable. Test-retest reliability with this method is extremely high, usually exceeding $0.90 .^{6}$

Foot position sense testing was performed under quasi-static conditions, that is, similar to locomotion insofar as the task required behavioural accommodation to foot support surface slope and maintenance of stable equilibrium when weight was transferred to the block, yet differing from locomotion in that there was no forward movement. Subjects estimated the perceived direction and amplitude of surface slope once they applied full body weight to a series of blocks. All subjects wore goggles which were modified with the addition of translucent adhesive tape to the bottom half of the lens in order to prevent them from viewing the blocks and using this information in judging surface slope. Estimates of surface slope were based on a ratio scale from zero to 15 , where zero corresponded to a horizontal surface and $15-37.5^{\circ}$. The $12.5^{\circ}$ difference between actual maximum slope and scale maximum was designed to allow overestimation of surface slope. Subjects were told that a surface angle might be repeated more than once during each testing condition although this never occurred. The order of presentation of surface blocks was counterbalanced across exercise first, and angles second. Subjects were given reference values of $0^{\circ}, 12.5^{\circ}$, and $25^{\circ}$ every 11 estimates. The method required subjects to stand vertically with $0^{\circ}$ flexion at the knee. This was ensured by instructions to subjects, and monitoring by the experimenter. Blocks were placed against a wall which provided support if balance was lost (Figure 1).

\section{Experimental procedure}

Subjects were told that the purpose of the experiment was to measure how ankle taping affects judgment of support surface angle. Written consent was obtained according to guidelines proposed in the Declaration of Helsinki of the World Medical Association. The right leg of subjects was first tested. Taped and untaped subjects participated in a 30 minute exercise session

Table 1. Mixed experimental design incorporating a repeated measures design across exercise condition and a between subjects design for taping condition. A total of 24 subjects was randomly assigned to one of the two ankle taping conditions. Measurements of foot position sense were taken before and after the exercise and no exercise conditions.

\begin{tabular}{|c|c|c|c|c|}
\hline \multirow[b]{2}{*}{ Ankle condition } & \multicolumn{2}{|c|}{ Exercise condition } & \multicolumn{2}{|c|}{ No exercise condition } \\
\hline & Pre-measurement & Post-measurement & Pre-measurement & Post-measurement \\
\hline Tape $(n=12)$ & 1 & 2 & 3 & 4 \\
\hline No tape $(n=12)$ & 5 & 6 & 7 & 8 \\
\hline
\end{tabular}




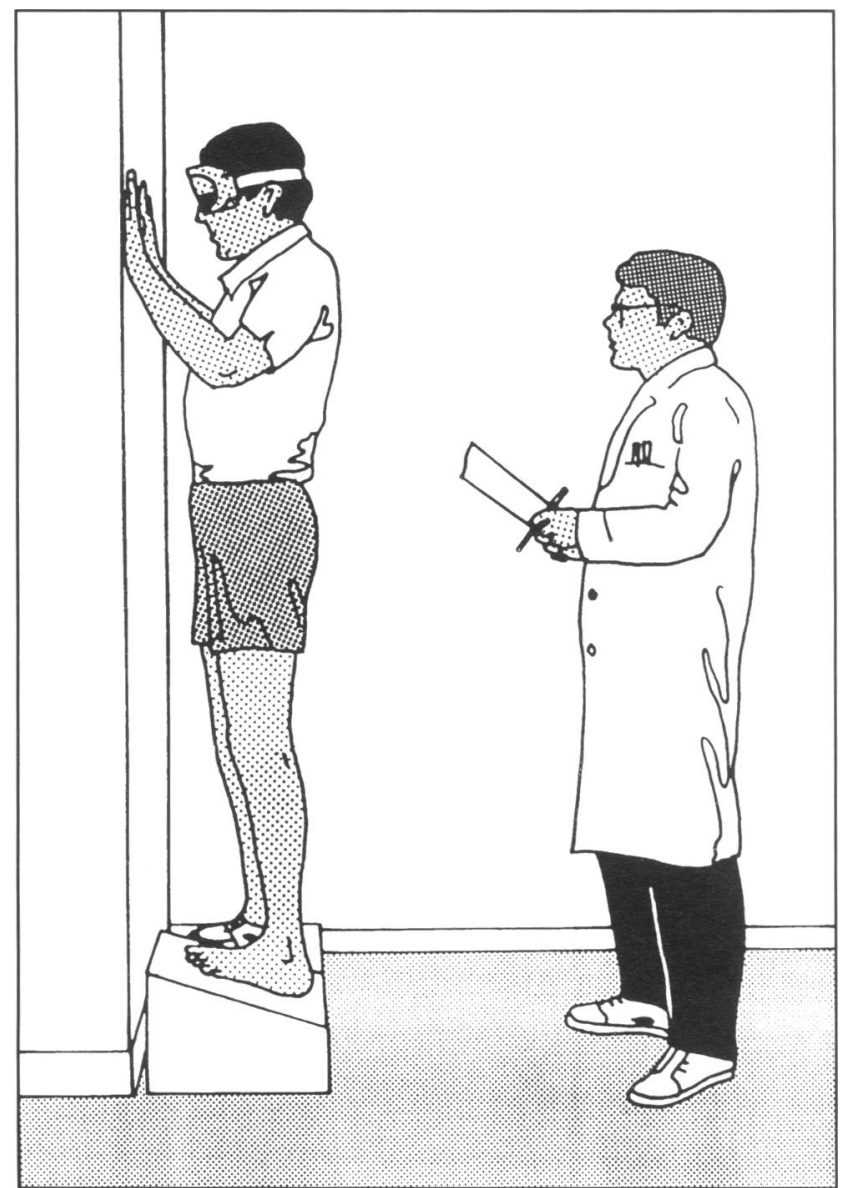

Figure 1. Sketch of experimental setup used in the present experiment. Subjects were asked to estimate perceived direction and amplitude of surface slope once they applied full body weight to a series of blocks when barefoot and when wearing footwear. A wall was used for support. Legs were straight.

consisting of running and basketball, whereas the noexercise subjects rested. The right leg was then re-tested following either the exercise or no-exercise sessions. The room where testing was performed was well lit and ventilated. Subjects exercised in a gymnasium above the testing room.

\section{Data analysis}

Foot position estimate error quantifies difference between perceived foot position derived from estimates of surface slope and actual slope of surface. Absolute mean estimate error assigns a positive value to errors, whether they be underestimation or overestimation of actual position. This measure gives the best indication of overall precision of estimates. Net mean estimate error is positive for overestimation and negative for underestimation of actual foot position. It indicates orientation of position error. Surface slope, net mean error, and absolute mean error were examined as a function of perceived surface slope using analysis of variance for repeated measures, according to a tape $x$ exercise $x$ angle design, in which the tape factor consisted of two levels (taped, untaped), exercise factor consisted of two levels (exercise, no-exercise), and angle factor consisted of 11 levels representing the angled blocks subjects were tested with $\left(0^{\circ}-25^{\circ} ; 2.5^{\circ}\right.$ increments). Post-hoc analysis was performed via Student $t$ tests with Bonferroni adjustment. Test method reliability was assessed using Pearson product moment correlation coefficient. The criterion for statistical significance was set at $\alpha=0.05$ for all tests.

\section{Results}

\section{Pre-exercise compared to no-exercise conditions}

There was no significant difference in perceived surface slope $[\mathrm{F}(10,220)=2.05, P<0.231]$, net mean estimate error $[\mathrm{F}(10,220)=3.50, P<0.112]$, and absolute mean estimate error $[\mathrm{F}(10,220)=2.61, P<0.216]$ for both taped and untaped subjects. This indicates no error due to condition order and subject selection.

\section{Foot position awareness as a function of slope plane}

There were no significant differences in perceived surface slope $[\mathrm{F}(30,476)=5.19, P<0.229]$, absolute mean estimate error $[\mathrm{F}(30,476)=6.89, P<0.201]$, and net mean estimate error $[\mathrm{F}(30,476)=12.11, P<0.156]$, in relation to plane of orientation of support surface. Consequently data from both sagittal and frontal plane orientations were combined for the analysis that follows.

\section{Perceived surface slope as a function of actual surface slope (Figure 2)}

All main effects and two way interactions were significant. There was a significant three way interaction effect for tape $\times$ exercise $\times$ angle $[F(10,220)=5.19$, $P<0.001]$.

\section{Absolute mean estimate error as a function of actual foot position (Figure 3)}

All main effects and two way interactions were significant. There was a significant three way interaction effect for tape $\times$ exercise $\times$ angle $[F(10,220)=4.03$, $P<0.001]$

\section{Net mean estimate error as a function of actual surface slope (Figure 4)}

All main effects and two way interactions were significant. There was a significant three way interaction effect for tape $\times$ exercise $\times$ angle $[F(10,220)=3.03$, $P<0.001]$

\section{Reliability of testing method}

The testing method displayed test-retest reliability coefficient of 0.91 for both taped and untaped subjects in the no-exercise condition. Test-retest reliability coefficient for the exercise condition was 0.89 . 

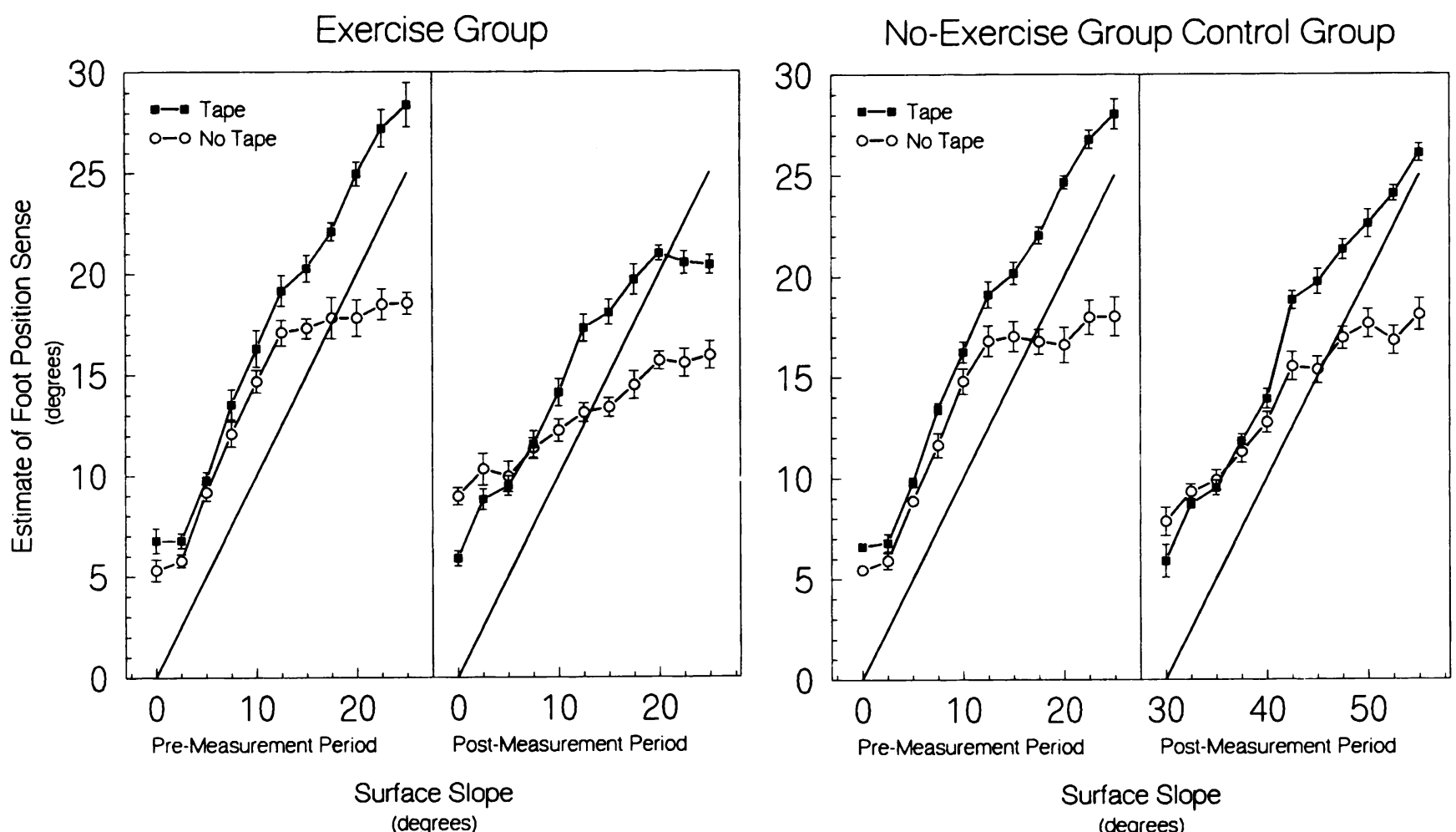

Figure 2. Perceived surface slope following a 30 min exercise session (left) and a 30 min no-exercise control session (right) for both taped and untaped subjects.
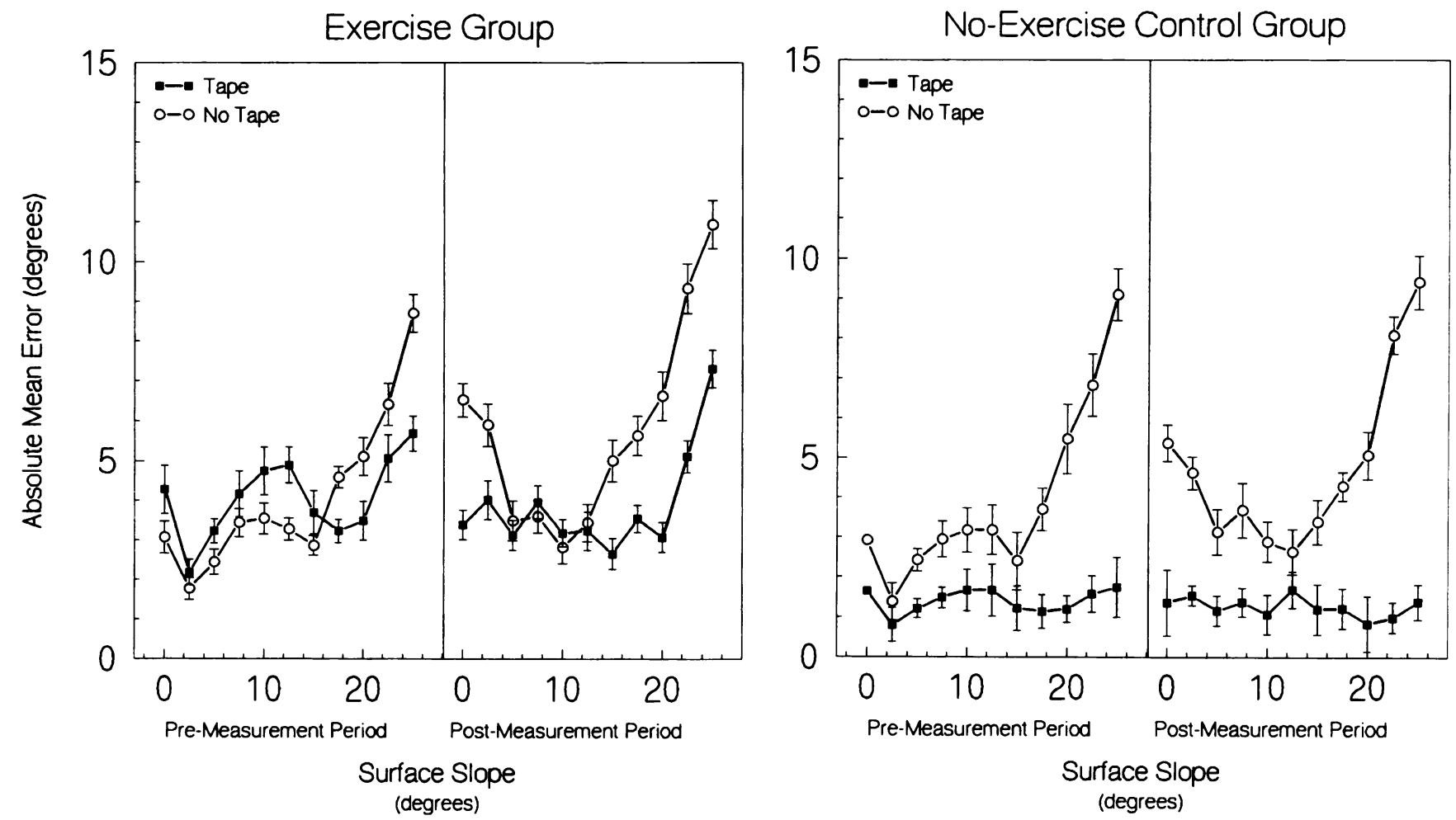

Figure 3. Absolute mean estimate error following a $30 \mathrm{~min}$ exercise session (left) and a 30 min no-exercise control session (right) for both taped and untaped subjects.

\section{Discussion}

Neurophysiological and perceptual investigations have shown that kinaesthetic sense-and therefore foot position awareness-is derived almost entirely from muscle and tactile receptors. ${ }^{9}$ Older notions assurned contributions from joint capsular receptors, unspecified articular surface receptors, ligament receptors, and 

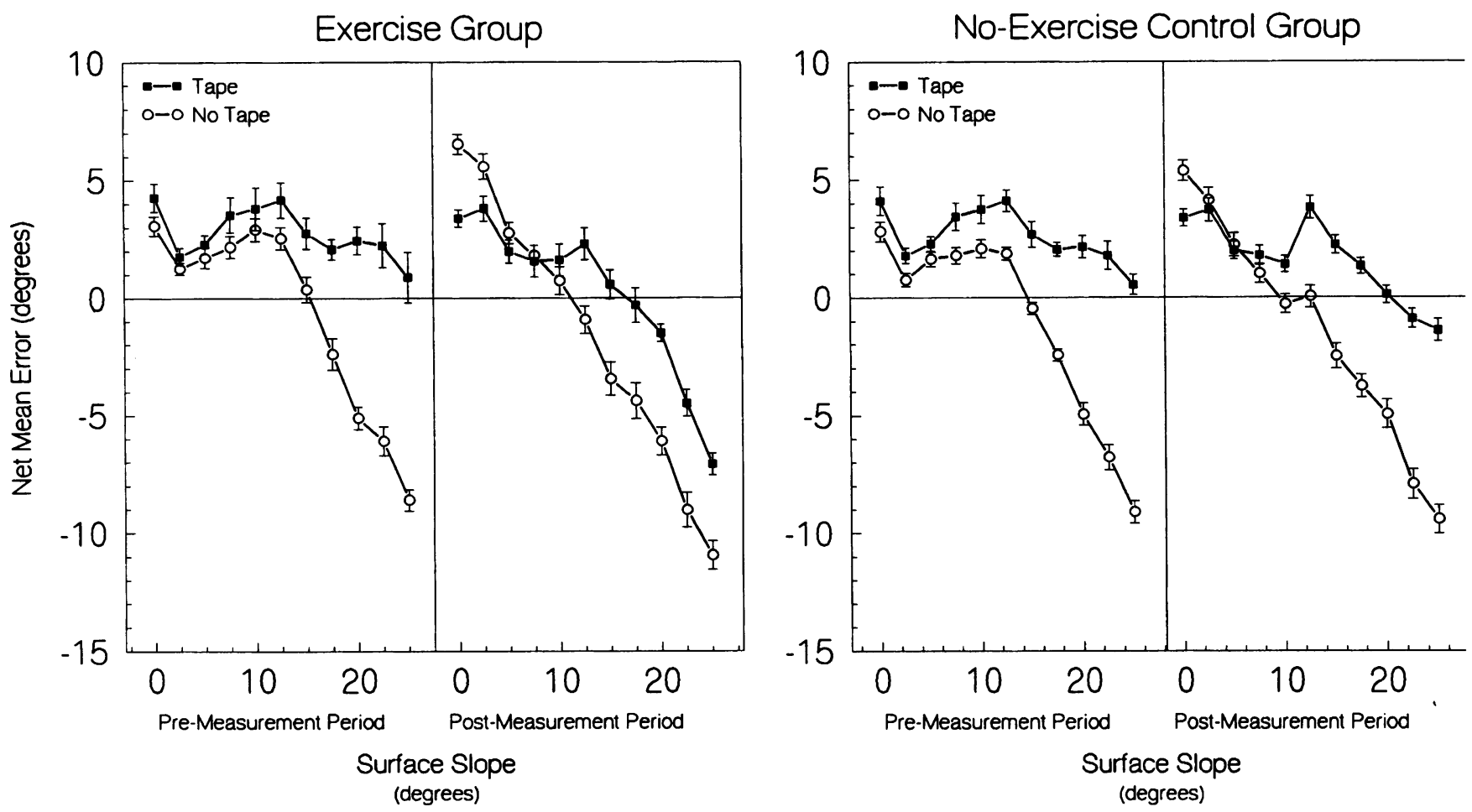

Figure 4. Net mean estimate error following a $30 \mathrm{~min}$ exercise session (left) and a $30 \mathrm{~min}$ no-exercise control session (right) for both taped and untaped subjects.

tendon organs. ${ }^{10}{ }^{11}$ Joint capsule and articular receptors play no significant role in kinaesthetic sense since total joint replacement, which presumably eliminates these influences, has no effect on joint position awareness. ${ }^{11}$ Furthermore, anaesthesia of joint ligaments causes no decline in joint position sense. ${ }^{12}$ Finally, discharge from primary afferents from tendon organs does not vary in relation to small changes in joint position, and therefore cannot account for precise joint position awareness. ${ }^{10}$

Our results indicate that taping influenced foot position awareness mainly when the surface slope was greater than $10^{\circ}$, presumably the range of interest regarding ankle injuries, considering that engagement of ligaments occurs in this range. Absolute error in this higher range was $4.34^{\circ}$ with tape and $5.15^{\circ}$ without it, $19 \%$ greater $(P<0.001)$. Untaped subjects wearing modern athletic footwear showed no position awareness whatsoever, and therefore could not distinguish between a flat surface and surface slope of $20^{\circ}$.

Overall, absolute mean estimate error was $3.95^{\circ}$ and $4.81^{\circ}$, before and after exercise, respectively-an increase of $22 \%$. The benefit of taping was fairly uniform throughout the range of surface slopes. $A b$ solute mean estimate error increased by $7 \%$ following exercise in the taped group, whereas the untaped group showed an increase of $39 \%$. Taping therefore showed its greatest benefit to foot position awareness following exercise.

Taped subjects moderately overestimated plantar surface slope before exercise (net error $1.59^{\circ}$ ) but error direction was neutral following exercise (net error $0.17^{\circ}$ ). Untaped subjects moderately underestimated actual surface slope (net error $-1.46^{\circ}$ ), which worsened modestly with exercise $\left(-1.58^{\circ}\right)$. The above evaluation masks imprecision of position sense at acute surface slopes, above $10^{\circ}$, which is probably most relevant to ankle sprains; therefore we analysed these data separately. With analysis restricted to surface slope of $10^{\circ}$ and greater, untaped subjects strongly underestimated surface slope before exercise (net error $-5.7^{\circ}$ ), and underestimated it further after exercise (net error $-6.78^{\circ}$ ). When taped, the direction of error was neutral before exercise, but changed to moderate underestimation (net error $-2.52^{\circ}$ ) after exercise. Since humans presumably command muscle contraction to support their foot relative to perceived foot position, underestimation of surface slope suggests inadequate support, the precondition for inversion injury according to the proprioception theory.

While taping improves foot position sense when humans wear athletic footwear, it remains poor compared to the barefoot condition if we use barefoot preexercise data available from a previous report for comparison..$^{13}$ Absolute foot position error was $4.11^{\circ}$, $3.13^{\circ}$, and $1.96^{\circ}$ for athletic footwear, athletic footwear taped, and barefoot, respectively. Therefore when compared to the barefoot condition, foot position awareness was $107.5 \%$ worse in untaped subjects with athletic footwear, and $58.1 \%$ worse in ankle taped subjects wearing athletic footwear. Since the most obvious difference between being barefoot and wearing shoes is that when barefoot the plantar surface is in direct contact with the weightbearing surface and subject to intense shear, it seems probable that information emanating from plantar cutaneous mechanoreceptors is required for precise foot position sense, as shown by McCloskey and Gandevia. ${ }^{9}$

The above data support the hypothesis tested: taping 
improves foot position awareness. A further conclusion is that taping counters underestimation of foot position angle caused by modern athletic footwear. The inescapable conclusion is that footwear use is ultimately responsible for ankle injury. The conclusion is consistent with observations made among populations where barefoot activity is the norm. Ankle sprains are uncommon in these groups. Since the benefit of taping remains even when ankle supporting function has declined (after exercise), there is support for the notion that traction of tape on the skin of the leg and foot is used by humans to judge foot position. ${ }^{5}$

In conclusion, this experiment provides the strongest physiological evidence yet presented of potential usefulness of ankle taping in sport. From another perspective it suggests that most ankle injuries are not inherent to sport, but rather are caused by footwear. Since ankle injuries may be the most common injury in sport, it follows that identifying and redesigning footwear to optimize this sense may well be the most promising approach to reducing injury incidence in all sports.

\section{Acknowledgements}

We thank Lynette Jones for suggestions related to perception. This work was supported in part by the Natural Sciences and Engineering Research Council of Canada Grant OGPIN 013, and the Helen McCall Hutchinson Clinical Gerontology Scholarship.

\section{References}

1 Garrack JG, Requa RK. The epidemiology of foot and ankle injuries in sports. In: Yokum LA, ed. Clinics in sports medicine: foot and ankle injuries. Philadelphia: W B Saunders, 1988: 29-36.
2 Mack RP. Ankle injuries in athletics. Clin Sports Med 1982; 1 : 71-84.

3 Bullard RH, Dawson J, Arenson DJ. Taping the "athletic ankle". Am J Podiatr Assoc 1989; 69: 727-34.

4 Perlman M, Leveille D, DeLeonibus J, et al. Inversion lateral ankle trauma : differential diagnosis, review of literature, and prospective studies. J Foot Surg 1987; 26: 95-135.

5 Karlsson J, Andreasson GO. The effect of external ankle support in chronic lateral ankle joint instability. Med Sci Sports Exerc 1992; 20: $257-61$.

6 Snoddgrass JG, Levy-Berger G, Haydon M. Psychophysical methods. In: Snoddgrass JG, Levy-Berger G, Haydon M. eds. Human experimental psychology. New York: Oxford University Press, 1985: 58-87.

7 Stevens SS. On the psychophysical law. Psychol Rev 1957; 64 : 153-81.

8 Knibestol M, Valbo AB. Intensity of sensation related to activity of slowly adapting mechanoreceptive units in the human hand. $J$ Physiol (Lond) 1980; 300: 251-67.

9 McCloskey DI, Gandevia SC. Role of inputs from skin, joints and muscles and of corollary discharges, in human discriminatory tasks. In: Gordon G, ed. Active touch: the mechanism of recognition of objects by manipulation: a multi-disciplinary approach. Oxford: Pergamon Press 1977: 177-88.

10 Browne K, Lee J, Ring PA. The sensation of passive movement at the metatarsophalangeal joint of the great toe in man. J Physiol (Lond) 1954; 126 : 448-58.

11 Clark FJ, Horch KW. Kinesthesia. In: Boff KR, Jauffman L, Thomas JP, eds. Handbook of perception and human performance. New York: John Wiley \& Sons, 1986: 13.1-13.62.

12 Goodwin GM, McCloskey DI. Matthews PBC. The persistence of appreciable kinesthesia after paralyzing joint afferents but preserving muscle afferents. Brain Res 1972; 38 : 326-9.

13 Gregory JE, Morgan DL, Proske U. Changes in size of the stretch reflex of cat and man attributed to aftereffects in muscle spindles. J Neurophysiol 1987; 58: 628-40.

14 Gregory JE, Morgan DL, Proske U. Aftereffects in the responses of cat muscle spindles and errors of limb position sense in man. $J$ Neurophysiol 1988; 59: 1220-30.

15 Gregory JE, Morgan DL, Proske U. Errors in position sense attributed to aftereffects in muscle spindles. (Abstract) Proc Aust Physiol Pharmacol Soc 1986; 17: 52P.

16 Robbins SE, Waked EG, MacClaran J. Proprioception and stability: foot position awareness as a function of age and footwear. Age Ageing 1995; 24 : 67-72. 